\title{
Responsabilidade moral razoável
}

Reasonable moral responsibility

\begin{abstract}
Resumo: O principal objetivo desse artigo é responder a questão sobre o que constitui a responsabilidade moral. Tentaremos demonstrar que a responsabilidade moral tem duas características centrais, a saber, exigências internalistas e autoridade social. Para tal propósito, faremos uso de estratégias compatibilistas. O próximo passo será tentar descrever a concepção de responsabilidade substancial de Thomas Scanlon e, no final desse artigo, estipularemos um argumento sobre um tipo de responsabilidade moral razoável que pode estar contida na teoria da justiça como equidade de John Rawls.
\end{abstract}

*Denis Coitinho

Palavras-chave: Responsabilidade. Coerentismo. Razoabilidade.

\begin{abstract}
The main aim in this article is to answer the question of what constitutes moral responsibility. We will attempt to show that moral responsibility has two essential features, that is, internalistic demands and social authority. For this purpose, we will make use of compatibilistic strategies. We will then attempt to describe Thomas Scanlon's view of substantive responsibility and, in the last part of the article, we will put forward an argument concerning a type of reasonable moral responsibility expressed in John Rawls' theory of justice as fairness.
\end{abstract}

Keywords: Responsibility. Coherentism. Reasonableness.

que significa dizer que alguém é responsável moralmente por sua ação? Significaria dizer que o agente é responsável por todas as consequências das ações? Ou, alternativamente, que ele seria responsável apenas pela intenção da ação? Ou, ainda, que ele seria responsável por sua identidade mental, o que incluiria sua personalidade, caráter,

\footnotetext{
* Professor do Programa de Pós-Graduação em Filosofia da UNISINOS, São Leopoldo, Brasil.
} Pesquisador do CNPq. 
emoções? É claro que quando falamos de responsabilidade moral estamos falando inicialmente de um âmbito em que haja o merecimento de elogio ou censura por uma ação. Também, é necessário que essa ação seja voluntária e que tenha passado por um processo de escolha deliberativa. Isso já releva um significado primário de responsabilidade moral, a saber, que ela se dá em um horizonte de exigências, de reivindicações. Mas, será que isso resolveria todo o problema? É possível que não, uma vez que temos diversos tipos de exigências em nossa vida social, tais como as profissionais, jurídicas, políticas, estéticas etc. Veja-se o caso de Alberto, um menino de dez anos que tem a responsabilidade de, todos os dias, após o almoço, retirar o lixo e colocá-lo no contêiner que fica em frente de sua casa. Há uma obrigação, uma exigência de que ele faça uma certa ação, por exemplo, retirar o lixo. Mas, parece que essa exigência não é propriamente moral, embora esteja no âmbito do elogio ou censura, além de estar no horizonte de uma ação voluntária e de escolha deliberada. $O$ que vai ser fundamental aqui é investigar a respeito da natureza dessas exigências morais, isto é, sobre as características específicas do que seria o moral e, também, sobre a natureza da autoridade dessas exigências. No exemplo de Alberto é fácil ver as características desse fenômeno: a ele é exigido a realização de uma ação que produza eficiência doméstica, pensando na repartição de tarefas entre uma família. Será elogiado se retirar o lixo. No entanto, se ele demorar no futebol e esquecer de seu dever, será reprendido, provavelmente por sua mãe e pai. Talvez, seja até punido com a perda da mesada. Será o mesmo no caso moral?

Vamos tomar como ponto de partida um exemplo para pensar sobre as características das exigências morais e do tipo de autoridade pressuposta a essas exigências. Vejamos o caso conhecido como o maníaco de Cleveland. Ariel Castro, de 53 anos, morador do bairro West Side, em Cleveland, Ohio, motorista de ônibus escolar e de origem porto-riquenha, raptou as jovens Amanda Berry, Michelle Knight e Gina de Jesus, as manteve em cárcere privado por 10 anos e, também, as estuprou sistematicamente durante todo esse tempo, além de torturá-las psicologicamente, como as obrigando a assistir as matérias televisivas sobre o seu próprio desaparecimento e a respectiva busca por parte de seus familiares. As jovens eram presas com cordas e correntes e ficavam com a boca tapada com fita adesiva para não gritarem. Na maioria das vezes, ficavam no porão, sem direito à luz do dia. Michelle Knight teria engravidado quatro ou cinco vezes de Ariel. Ela, entretanto, teria perdido os bebês em razão de ter sido espancada na barriga e privada de comida por duas semanas para forçar o aborto. Amanda Berry teve uma filha no cárcere, Jocelyn, hoje com seis anos. Ariel foi preso no dia 6 de maio de 2013, logo após Amanda ter quebrado a porta da casa e 
pedido por socorro aos vizinhos ${ }^{1}$. O promotor, Timothy McGinty, pensou em pedir a pena de morte para Castro, isso em razão de considerar que os atos de sequestro, cárcere privado, estupro, tortura e assassinato (abortos forçados) teriam sido deliberados e, logo, teriam sido atos livres do agente, e isso significaria que Ariel teria tido o livre arbítrio para escolher a ação e, logo, seria responsável por ela. Como escolheu estuprar e matar, por exemplo, ele mereceria uma forte censura e uma punição capital. Isso claramente pode ser identificado como uma posição libertista ou indeterminista de responsabilidade moral, uma vez que o agente é tomado como responsável moralmente por seus atos em razão de sua liberdade ou livre-arbítrio². Outra maneira de ver o caso, é procurar apontar para as causas alheias à vontade de Ariel que teriam determinado os atos brutais, tais como abusos sofridos na infância, predisposição genética, insanidade etc. Foi essa linha de raciocínio que foi adotada pelo advogado de defesa de Ariel, Craig Weintraub, linha de defesa que pode ser identificada como determinista, uma vez que procura atenuar a responsabilidade moral do agente em razão da não voluntariedade da ação ${ }^{3}$. A defesa e o próprio acusado procuraram frisar a todo momento que os crimes foram cometidos não por Ariel ser um monstro, mas por ele ser uma pessoa doente e, inclusive, viciado em pornografia. Importante ressaltar que o juiz responsável pelo caso, amparado por avaliações psiquiátricas, julgou Ariel mentalmente competente para enfrentar o julgamento. Outro fato importante foi que a imprensa divulgou um bilhete de Ariel que foi encontrado em sua casa e que teria revelado traços de sua personalidade obscura. No bilhete, ele teria se definido como 'predador sexual' e teria revelado sua intenção de cometer suicídio. Ao

Para mais detalhes desse caso, ver matéria de Max Ehrenfreund no jornal The Washington Post em 9 de julho de 2013.

2 O argumento libertista ou indeterminista pode ser formulado da seguinte maneira: (1) Para uma pessoa ser responsável por uma ação ela precisa ser livre; (2) As pessoas possuem livre-arbítrio, isto é, liberdade; (3) Logo, se pode atribuir responsabilidade moral às ações das pessoas. O argumento libertista pode ser encontrado paradigmaticamente em Kant, uma vez que, para ele, uma ação adquire valor moral quando é feita por dever e não apenas conforme o dever, o que pressupõe a liberdade do agente para a escolha. A ação moral tem valor por ser autônoma, e isto significa não ser causalmente determinada. Assim, a responsabilidade do agente se dará por sua capacidade de pertencer ao reino dos fins de forma a se conduzir pelas máximas da liberdade antes que por determinações naturais. Ver especialmente a terceira seção da Fundamentação da Metafísica dos Costumes (KANT, 2010, p. 52-66).

3 O argumento determinista pode ser apresentado na seguinte forma: (1) Para uma pessoa ser responsável por uma ação ela precisa ser livre; (2) Todas as ações humanas são determinadas de uma certa forma; (3) Logo, não se pode atribuir responsabilidade moral às ações das pessoas. Vejamos um exemplo dessa posição determinista. O behaviorismo de Skinner entende o comportamento humano como uma consequência (resposta) do ambiente (estímulo) que é externo à vontade do agente, o que implicaria negar a liberdade e a consequente responsabilidade dos seres humanos. Ver, especialmente, o capítulo 1 do livro The Behavior of Organisms: an experimental analysis (SKINNER, 1938, p. 3-43). 
final, o advogado de defesa fez um acordo com a promotoria de forma que se Ariel confessasse os crimes, ele não seria sentenciado a pena de morte. Também, a destruição da casa de Ariel fez parte desse acordo. No julgamento, Ariel confessou os crimes, se declarando culpado de 937 das 977 acusações feitas, pediu perdão às vítimas e foi sentenciado à pena perpétua e mais 1.000 anos de prisão. Em torno de um mês depois da sentença, foi encontrado morto em sua cela, enforcado com um lençol. A perícia atestou suicídio por enforcamento 4 .

O que esse caso revela para nossa questão a respeito da natureza das exigências morais e a respectiva autoridade? Uma primeira constatação é que essas exigências parecem revelar uma característica internalista, de um internalismo de razões, uma vez que os agentes aprovam ou desaprovam certos comportamentos tantos nos outros como em si mesmos. No caso em questão, há uma exigência que certos atos não devem ser cometidos por serem errados, como o sequestro, estupro, assassinato e tortura. Essa exigência releva uma atribuição de liberdade e responsabilidade que os indivíduos fazem aos outros e a si próprios. É diferente no caso de Alberto, uma vez que a exigência de retirar o lixo é externa a ele próprio, sendo apenas funcional ${ }^{5}$. É claro que essa exigência é social, também, mas o específico é que ela releva um aspecto constitutivo da identidade dos cidadãos de uma dada sociedade, a saber, que espera dos outros e de si próprio um certo tipo de comportamento, isto é, um comportamento que siga determinados critérios normativos, tais como, imparcialidade ou mesmo reciprocidade, por exemplo. Com isso já se pode ver, também, que a autoridade dessas exigências é claramente social. Há um padrão moral que é defendido por uma sociedade que cobra um certo tipo de comportamento de seus cidadãos. Importante ressaltar que essa responsabilização não é apenas jurídica, pois mesmo antes de Ariel ter sido julgado, ele parece ter sido condenado moralmente pela opinião pública mundial. Em muitas situações, a força da punição parece ser proporcional ao peso moral que é dado a uma certa ação. Independentemente do caso de Ariel ter recebido a pena de

4 Para mais detalhes do julgamento e sentença, ver a matéria de Tim Walker no jornal The Independent em 01 de agosto de 2013. Para detalhes adicionais sobre o suicídio de Ariel na prisão, ver a matéria de Mark Peters no The Wall Street Journal em 04 de setembro de 2013.

5 O ponto central que está sendo afirmado é que a esfera moral é caracterizada por um âmbito de justificação em primeira pessoa, uma vez que é a nossa aprovação que justifica uma ação no âmbito moral, o que implica pensar que esse âmbito é claramente prescritivo antes que puramente descritivo. Sobre o tema, ver a distinção que Christine Korsgaard realiza entre explicar uma ação e justificar uma ação a partir de seu argumento contra o naturalismoevolucionismo. Uma ação explicada em termos naturais não é o mesmo que uma justificação da ação sobre uma base interna, em primeira pessoa, uma vez que é a nossa aprovação interna que justifica a ação, indo além da pura externalidade de terceira pessoa. Ver KORSGAARD, 1996, p. 7-16. 
prisão perpétua como punição por seus atos ao invés da pena de morte, continuará havendo uma exigência normativa em primeira pessoa (do singular ou mesmo do plural) para os membros da comunidade moral que circunscreve, propriamente dito, o âmbito moral. Talvez, o fato da casa em que tudo aconteceu ter sido destruída logo após a sentença aponte para esse fenômeno que estamos procurando ressaltar.

Com essa delimitação da questão da responsabilidade moral e deixando de lado as posições incompatibilistas, como são as do determinismo e libertismo, procuraremos fazer uso de uma posição compatibilista que pode ser vista nas teorias neocontratualistas para melhor compreender o que está em jogo quando responsabilizamos moralmente alguém ou a nós mesmos em uma dada situação. Esse modelo parece fazer uso de uma concepção de responsabilidade moral que não está fundada na liberdade ontológica do agente, isto é, que não se baseia na defesa da liberdade da ação de um ponto de vista metafísico, ponto de vista do livre-arbítrio, o que resultaria em ter que provar a falsidade do determinismo, além de ter que assumir uma tarefa mais complexa, a saber, provar a verdade da tese indeterminista, o que significaria em ter que provar a existência da liberdade como um fato. Antes, parece fazer uso de uma concepção de responsabilidade moral razoável, compreendendo a responsabilidade do agente na possibilidade do indivíduo deliberar de uma certa forma, e isso em estreita harmonia com os deveres que são assumidos socialmente, o que gera direitos que são políticos. Assim, a estratégia será olhar para a liberdade não de uma forma metafísica, mas tomar a responsabilidade como uma prática social, partindo das relações entre as pessoas que atribuem responsabilidades umas às outras, isto é, que fazem exigências recíprocas. Dessa forma, a responsabilidade se encontraria em um âmbito que é também político e jurídico, preferencialmente a um universo que seria puramente moral.

No restante do texto, procuraremos esclarecer a respeito da especificidade tanto das exigências morais quanto de sua respectiva autoridade, ressaltando algumas estratégias dessa posição compatibilista e, depois, apresentaremos a concepção de responsabilidade de T. Scanlon e, por fim, apresentaremos a concepção de responsabilidade moral razoável que pode estar contida na justiça como equidade de J. Rawls. Ressalta-se que as estratégias utilizadas fazem uso de uma epistemologia coerentista, de forma a pensar a justificação de critérios normativos, como princípios, por exemplo, em razão de sua coerência com um sistema coerente de crenças, partindo, muitas vezes, dos próprios juízos morais convergentes de uma sociedade democrática, plural e tolerante para alcançar a justificação e a consequente responsabilização. 
Vamos olhar mais atentamente sobre o que significa dizer que as exigências morais se dão em um universo internalista. Retomemos o caso de Ariel. Independentemente da sentença de prisão perpétua, a opinião pública condenou gravemente os atos realizados por ele. O que isso mostra? Que as pessoas viam Ariel como alguém livre, que pôde escolher entre estuprar ou refrear seu desejo e, em razão disso, o responsabilizaram por seus atos. Como o viam como alguém livre, sentiram indignação pelo que ocorreu. Assim, esse sentimento moral de indignação já revela uma interessante característica de como as pessoas veem os outros e a si mesmas, a saber, como seres capazes de liberdade, que podem escolher entre fazer ou não uma dada ação e, em razão dessa capacidade de escolha, se veem como responsáveis moralmente por essa escolha. Não se trata de um pressuposto ontológico; antes, ele é pragmático. Esse argumento foi utilizado de forma seminal por Peter Strawson, a saber, que a existência de atitudes reativas mostra que o outro é visto como livre e responsável por sua ação ${ }^{6}$. Atitudes reativas como ressentimento, gratidão e indignação, por exemplo, são sentimentos morais que atribuem responsabilidade moral ao agente, uma vez que o mesmo se vê e vê os outros como podendo agir diferentemente. Também as atitudes autorreativas, como culpa, remorso, vergonha, mostrariam o mesmo fenômeno, a saber, uma atribuição de liberdade e responsabilidade ${ }^{7}$.

6 As atitudes reativas são aquelas em que um agente reage frente a alguma ação cometida por alguém. São exemplos de atitudes reativas a gratidão, ressentimento, perdão, amor, sentimentos feridos. Ocupa um espaço de destaque a atitude de ressentimento. Para Strawson, o ressentimento é um sentimento moral que se origina em uma situação em que uma pessoa é ofendida pela ação de outra e sente que essa pessoa não deveria ter agido daquela forma. É uma reação a uma qualidade dos outros em relação a nós, como manifestada em seu comportamento. Por isso, esse tipo de atitude revela uma atribuição de liberdade e a consequente responsabilidade aos agentes, uma vez que não se poderia sentir ressentimento pelas injúrias contadas por alguém que sofre de uma grave deficiência mental, e isso em razão desse agente ser tomado como determinado e não como livre. Importa frisar que mesmo que o determinismo fosse verdadeiro, ele não teria efeito sobre a vida prática das pessoas, uma vez que os indivíduos assumiriam relações interpessoais com base na pressuposição de não-determinação. Ver STRAWSON, 2008, p. 5-14.

7 Essa dimensão de arrependimento, culpa e remorso de um agente por sua escolha-ação demonstra um forte aspecto internalista, de primeira pessoa, como bem demonstrado por Bernard Williams. Williams usa o termo técnico 'agent-regret' para explicar o arrependimento como um sentimento internalista de culpa que tem como conteúdo psicológico o remorso e que se expressa pela tentativa de reparação, distinguindo-o de um arrependimento puramente externalista, circunstancial. Essa seria a diferença entre o arrependimento 'internalista' de Ana Karenina por escolher Vronsky e o arrependimento de um caminhoneiro que atropela uma criança que se joga embaixo de seu caminhão. É importante frisar que, para Williams, a responsabilidade se dá sobre a escolha do agente; mas, como a escolha só será justificada retrospectivamente em razão de seu sucesso ou fracasso, a responsabilidade é mitigada. Ver WILLIAMS, 1981, p. 26-30. 
Essa parece ser uma importante diferença entre os casos de Alberto e Ariel. Ariel poderia ter se sentido culpado pelo que fez, enquanto não faria sentido pensar que Alberto sentiria culpa por não ter retirado o lixo. Talvez poderia se sentir culpado por não ter obedecido a seus pais, o que remeteria a culpa por ter quebrado alguma promessa. Da mesma forma, não faria sentido pensar que os pais de Alberto se sentiriam indignados por seu filho não ter levado o lixo para fora. A indignação faria sentido em razão da desobediência e da quebra de confiança, mas não pelo ato cometido, até porque não retirar o lixo não parece ser um ato errado do ponto de vista moral, uma vez que o grande malefício causado seria, talvez, apenas a presença do mau cheiro dentro de casa. Com isso, podemos ver mais claramente de que forma a presença desses sentimentos revelam uma importante característica da moralidade, a saber, eles expressam uma dimensão interpessoal da existência humana, de forma que falar de responsabilidade moral exigirá a pressuposição de uma comunidade moral.

Talvez uma forma mais evidente para se compreender esse aspecto internalista da moralidade que estamos chamando atenção seja apontar para o papel da vontade do agente no momento de sua escolha entre fazer ou não uma dada ação, ou mesmo na escolha de um critério normativo para subsidiar sua ação. Mesmo admitindo que a tese determinista seja verdadeira, a saber, que todo evento tem uma causa e que antecedentes e leis físicas determinam todas as ações humanas, será que não poderíamos imaginar o determinismo como compatível com a liberdade da vontade, de forma a evidenciar a escolha como um tipo de ação que não será

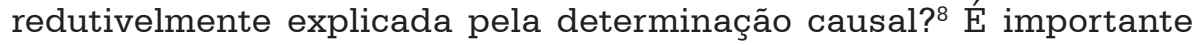

3 O argumento pode ser expresso da seguinte maneira: (1) Todo evento tem uma causa, sendo que antecedentes e leis físicas determinam todas as ações humanas; (2) Entretanto, o determinismo é compatível com a liberdade da vontade; (3) Assim, se pode assumir responsabilidade moral pelas ações realizadas sob a liberdade da vontade. Essa posição guarda fortes semelhanças com a de Frankfurt, em razão dele conectar a responsabilidade com a liberdade da vontade, uma vez que se a pessoa é aquele ente que possui a capacidade de apreciar a liberdade da vontade, que significa a satisfação de certos desejos de segunda ordem ou de ordens elevadas, ela deve ser responsabilizada pela sua ação, uma vez que sua vontade não é determinada causalmente. Assim, a pessoa que tem liberdade de ação é livre para fazer o que quer; tendo liberdade da vontade, a pessoa é livre em querer o que sua vontade quer, ou em querer o que ele deseja querer. Mas sobre a questão se a pessoa é moralmente responsável pelo que fez, isso não está conectado em saber se a pessoa estava em uma posição de ter a vontade que ela desejava. Para Frankfurt, é um erro achar que alguém age livremente apenas quando ele é livre para fazer o que ele quer ou que ele age por seu livre-arbítrio apenas se sua vontade for livre. A conclusão é que essa concepção de liberdade da vontade de Frankfurt parece ser neutra no que diz respeito ao problema do determinismo ou livre-arbítrio, uma vez que o agente (pessoa) é responsável por sua ação em razão de apreciar a liberdade da vontade ou falhar nessa apreciação, o que possibilita a escolha do agente que, mesmo sendo determinada, não invalidaria sua responsabilidade. Ver FRANKFURT, 1971, p, 17-20. 
deixar claro que não se pretende falar de um ponto de vista sub specie aeternitatis, de onde a escolha do agente seria totalmente livre de influências externas e a vida moral como inteiramente ligada à decisão livre, autônoma e responsável do sujeito. Não se está pretendendo uma vontade incondicionada; antes, gostaríamos de pensar na possibilidade de convivência entre uma escolha voluntária e deliberada com as circunstâncias exteriores à vontade do agente, que leva em consideração, inclusive, a sorte, sobretudo a constitutiva ${ }^{9}$.

Vejamos, então, o que constituiria a escolha moral como um tipo de ação não determinada. Em primeiro lugar, dizer que a escolha é um tipo de ação não determinada não implica afirmar que essa ação é incausada. Isso quer dizer que se poderia explicá-la em termos causais, embora a descrição dessa ordem de causalidade não abordaria nada do que não fosse fisicamente explicado. Dito de outra forma, ela poderia explicar os desejos de primeira ordem de um agente, mas não os seus desejos de segunda ordem. Veja-se o interessante exemplo dado por Frankfurt de um psiquiatra que trabalha com drogados e acredita que sua habilidade para auxiliar seus pacientes seria aprimorada se ele entendesse melhor o que é para eles o desejo pela droga da qual eles são viciados. Ele deseja ser movido por um desejo de tomar a droga, mas não deseja que esse desejo seja efetivo. O ponto central é que se poderia descrever o desejo de tomar drogas, que seria um desejo de primeira ordem, o desejo de fazer X, mas não se poderia descrever o desejo de segunda ordem, que seria um desejo de desejar fazer $\mathrm{X}^{10}$. Qualquer tentativa aqui de descrição implicaria em fracasso. Em segundo lugar, a escolha é um tipo de ação que está associada à deliberação, que é um ato de pesar razões alternativas. Sendo assim, a escolha é a conclusão de uma deliberação que decide pela melhor razão ou pelas melhores razões. Ressalta-se que esse ponto será explicitado nas duas seções seguintes. O último aspecto que queremos chamar atenção é para o âmbito social dessa escolha, que deve levar em consideração as melhores consequências do ato, o

9 Thomas Nagel também defende uma posição compatibilista de responsabilidade, de forma que o que uma pessoa faz depende de fatores que vão além de seu controle interno, sendo as influências externas importantes para o juízo moral, como no exemplo do oficial de um campo de concentração que poderia ter tido uma vida normal e tranquila se os nazistas não tivessem assumido o poder na Alemanha. Assim, Nagel conecta a questão da sorte com a responsabilidade moral, o que evidenciaria um paradoxo entre o agente parecer livre e ser determinado. Ver NAGEL, 1993, p. 58-60. Sobre o choque entre os pontos de vista interno e externo e a consequente insolubilidade do problema da responsabilidade, ver NAGEL, 1986, p. $120-124$.

10 O que importa para Frankfurt é identificar o desejo que motiva o agente para uma ação e a isso ele chama de vontade (will). A conclusão é que a vontade não é coextensiva à noção do que um agente pode fazer. Antes, é identificada com a noção de um desejo efetivo que move a pessoa à ação. Ver FRANKFURT, 1971, p. 7-9. 
que inclui levar em conta, inclusive, o papel da estabilidade social para a justificação. Voltemos ao caso de Ariel. Dizer que ele foi responsável moralmente pelos atos descritos seria dizer que ele teve a capacidade de escolher de uma forma não determinada. Por mais que se possa explicar as causas naturais do desejo de fazer tais atos, isso não explicaria nada a respeito do desejo de não desejar fazer tais e tais atos, ou da ausência desse desejo de segunda ordem. Mas isso não seria consequência de seu próprio caráter? A resposta é sim, mas para além do importante papel da sociedade e natureza em sua constituição, defende-se que o agente é sempre responsável por seu próprio caráter, de forma a ser responsável pelas ações virtuosas ou viciosas que formarão seu caráter. Note-se que o livre-arbítrio não é apenas escolher um curso de ação ou outro, mas fazê-lo a partir de uma capacidade de comandar as vontades. Se ver como livre é se ver como capaz de comandar as vontades e como capaz de justificar porque se escolheu que a vontade fosse uma e não outra. No caso de Ariel isso é significativo, pois como ele poderia ter justificado publicamente seus desejos e suas ações, a não ser apelando para o argumento da doença? Até mesmo a sua família ficou absolutamente chocada com o caso e pediu desculpas veementes às vítimas e seus familiares.

Passemos agora à abordagem sobre o tipo de autoridade pressuposta a essas exigências morais e sua importante conexão com a questão da punição. Em uma concepção de responsabilidade total, a autoridade das exigências é a de um ponto de vista absoluto, como seria a vontade divina, a razão tomada aprioristicamente ou, mesmo, as emoções. Mais relevante é identificar que esse tipo de autoridade seria absoluta e sua demanda seria individual, de forma que um indivíduo seria cobrado para agir de uma certa maneira, sendo moralmente responsável por um ato em razão do livre-arbítrio ${ }^{11}$. Veja-se que uma teoria retributivista da punição parece fazer uso dessa forma de autoridade absoluta, uma vez que o indivíduo é tomado isoladamente como um agente livre e responsável, sendo a punição um castigo pela ação incorreta, que é agravada em razão de sua liberdade. O ponto que se quer defender é que não precisaríamos estipular uma autoridade absoluta para pensarmos em um tipo de responsabilidade mais modesta, que recairia apenas na escolha razoável do agente sobre um princípio ou certo traço de caráter

${ }_{11}$ Scanlon chama essa responsabilidade total de responsabilidade como atributabilidade (responsibility as attributability), a caracterizando como no âmbito de uma ação que pode ser atribuída a um agente com base em algum elogio ou censura moral, devendo o agente agir livremente, a distinguindo de uma responsabilidade substancial (substantive responsibility), que se dá no âmbito das obrigações pessoais que recaem sobre o valor da escolha. A principal diferença é que a responsabilidade como atributabilidade recai sobre o caso da ação ser livre e não sobre o papel da escolha do agente. Ver SCANLON, 1998, p. 248-249. 
para julgar a correção dos atos. Nessa nova perspectiva, a autoridade dessas exigências morais seria essencialmente social. E isso poderá estar associado a uma teoria não retributivista da punição, que não conectaria necessariamente a voluntariedade da ação ao castigo, ressaltando o propósito de garantia da estabilidade social. Nesse esquema alternativo, o indivíduo seria punido não em razão de seu exclusivo merecimento, por ser sua ação livre, voluntária, mas porque isso também é eficaz socialmente. Isso nos remeteria em tomar a responsabilidade como um fenômeno social preferencialmente do que vê-la como um problema metafísico $^{12}$. No caso de Ariel, por exemplo, a punição teria muito mais o papel de impedir que outros atos similares venham a acontecer no futuro do que retribuir, pela pena, o mal que teria sido cometido de forma livre. Abandonando o ponto de vista do olho de Deus, não parece ser inteligível e mesmo eficiente essa concepção de justiça retributivista.

Outra forma de apontar para a natureza social da autoridade das exigências morais é evidenciar que a responsabilidade pode ser tomada como uma prática social, sendo vista a partir das relações entre as pessoas que fazem exigências mútuas. Lembremos que o argumento do determinismo faz uso da afirmação de que se tudo é causado, então, não existiria livre-arbítrio e, logo, ninguém seria responsável por sua ação. Uma interessante estratégia pode ser a de não olhar para a liberdade de uma forma metafísica, mas investigá-la a partir das relações entre as pessoas que atribuem responsabilidade umas às outras. Veja-se que não é preciso uma prova ontológica da liberdade para atribuir responsabilidade aos indivíduos, uma vez que temos responsabilidade jurídica e política sem fazer uso desse recurso último ${ }^{13}$. Por que, então, seria esse recurso

${ }_{12}$ Nowell-Smith parece defender uma posição compatibilista nessa mesma linha, tomando a responsabilidade em seu sentido social preferencialmente do que em seu sentido metafísico. Em "Freewill and moral responsibility", ele parece defender o seguinte argumento: (1) Mesmo o determinismo sendo verdadeiro, a responsabilidade é necessária para a punição e aprovação moral dos sujeitos; (2) Essas atitudes de aprovação e punição moral asseguram a estabilidade social, a ordem social; (3) Logo, o sujeito deve ser responsabilizado. Isso implicaria afirmar que conceitos de obrigação e responsabilidade não perderiam sua razão de ser mesmo sendo verdadeira a tese do determinismo, e isso em razão da eficácia social das práticas de punição e aprovação moral que favoreceriam a regulação social. Ver NOWELL-SMITH, 1948, p. 52-54.

13 Daniel Dennett parece defender uma posição compatibilista semelhante ao ver a liberdade do ponto de vista social e político. Ele destaca que a tomada de decisão humana é real e, assim como a linguagem, música e dinheiro, está em um âmbito de decision-making. Ele defende uma concepção naturalizada de livre-arbítrio e tomada de decisão, o que deixa bastante espaço para a responsabilização dos agentes. Assim, a natureza dá capacidade ao agente de escolher princípios (representações) para viver em conjunto, sendo a responsabilidade circunscrita a essa escolha das melhores alternativas. Ele parece se valer de um tipo de equilíbrio reflexivo: "Nós temos que usar nossos valores comuns como o ponto de partida para qualquer reavaliação meditada dos valores, mas da nossa perspectiva sobre nossos valores correntes mais altos, nós podemos formular, criticar, revisar, e - se tivermos sorte-endossar mutuamente um conjunto de princípios desenhados para viver em sociedade" (DENNETT, 2003, p. 268). 
necessário para o âmbito moral? Nessa perspectiva prática e social da responsabilidade, apenas seria necessário estabelecer o que faz uma ação ser tomada como certa ou como errada. Dito de outra forma, teríamos que especificar como se justifica uma crença moral. Tomando o coerentismo como um modelo mais eficiente do que os padrões epistemológicos alternativos, como os do fundacionismo, ceticismo, contextualismo ou mesmo fundacionismo moderado, uma crença moral seria justificada por sua coerência com um sistema integrado de crenças coerentes, o que incluiria princípios, ideais e até crenças não morais ${ }^{14}$. Por exemplo, para além da responsabilidade jurídica e política de Ariel em cumprir as leis e obedecer aos acordos, ele teria, também, como membro de uma comunidade moral, a responsabilidade de verificar se suas crenças morais, convicções, desejos, emoções seriam corretas segundo um padrão moral socialmente reconhecido. Tal qual uma sociedade política, uma comunidade moral parece só se efetivar a partir do compromisso dos agentes em seguir as regras estabelecidas.

\section{III}

O que dissemos até aqui pode ser sumarizado da seguinte maneira: a responsabilidade moral pode ser compatível com a verdade do determinismo em razão de se tomar a escolha moral como um tipo de ação não determinada que pode conviver com as circunstâncias exteriores à vontade do agente. $\mathrm{E}$, para que uma escolha seja tomada como uma ação não determinada, ela precisa possuir as seguintes características: ser voluntária, concluir um processo deliberativo e estar em um âmbito social. Precisamos agora explicar com mais detalhes essa segunda característica da escolha, a saber, a deliberação. Vejamos que a escolha moral é um tipo de ação que está associada à deliberação, que é um ato de pesar razões alternativas, sendo a conclusão de uma deliberação que decide pelas melhores razões. Para entender esse processo deliberativo, apresentaremos as linhas gerais da concepção de responsabilidade defendida por Scanlon que ressalta fortemente o valor da escolha do agente.

${ }_{14}$ Ronald Dworkin propõe um interessante método coerentista para o estabelecimento da justificação das crenças morais. Ele usa uma metáfora do filtro. As convicções morais mais fortes devem servir de filtro para outras influências subjetivas, como emoções, preconceitos, gostos, preferências. Assim, as convicções morais que são coerentes com outras convicções morais são convicções reflexivas e servem de filtro para a vontade do agente. Ver DWORKIN, 2011, p. 107-109. Nas palavras de Dworkin: "Moral responsibility requires that these other influences pass through the filter of effective convictions so that they are censored and shaped by those convictions, as light passed through a filter is censored and shaped" (DWORKIN, 2011, p. 108). 
Thomas Scanlon defende uma posição compatibilista, propondo a compatibilidade da tese causal com a responsabilidade moral, de forma a poder explicar os deveres comuns que são escolhidos de uma forma não determinística. Isto quer dizer que mesmo o determinismo sendo verdadeiro, a responsabilidade moral ainda seria possível, pois se basearia na escolha do sujeito sobre os deveres comuns, escolha essa que não é determinada por leis causais. Scanlon procura mostrar que o valor da escolha não é meramente instrumental, mas, também, é representativo e simbólico. Mais importante, que esses valores da escolha (preditivo, representativo e simbólico) podem ser usados de fundamento para a rejeição razoável de um princípio, como, por exemplo, um princípio paternalístico de interferência ${ }^{15}$.

Scanlon parece utilizar um argumento compatibilista semelhante ao de Peter Strawson, uma vez que, mesmo o determinismo sendo verdadeiro, ele não anularia o valor instrumental, representativo e simbólico de nossas escolhas, da mesma forma que, para Strawson, a verdade do determinismo não anularia a atribuição pragmática de liberdade que é assegurada pelas atitude reativas.

Esse argumento compatibilista pode ser apresentado da seguinte forma:

1. Para uma pessoa ser responsável por uma ação ela deve ser realizada a partir de uma escolha do sujeito;

2. Mesmo a tese do determinismo sendo verdadeira, ela não anularia o valor instrumental, representativo e simbólico da escolha;

3. Logo, as pessoas são responsáveis por suas ações (SCANLON, 1998, p. 251-256).

Vejamos mais detalhadamente o papel que o valor da escolha desempenha em determinar quais princípios são razoáveis rejeitar. Scanlon explica o papel da escolha na justificação dos princípios morais

15 O ponto essencial de Scanlon é mostrar que a escolha não tem apenas um valor instrumental, preditivo, mas, também, representativo e simbólico. Vejamos a diferença entre eles. No valor instrumental ou preditivo, a escolha envolverá uma satisfação futura, como escolher um prato do cardápio em um restaurante. Aqui, a escolha é um instrumento para um futuro prazer. Mas isso não esgota todas as formas de escolha. Outra forma de escolha possui um valor representativo, como no caso de se escolher um presente para a esposa. Aqui, a escolha que se faz representa quem se é. O valor simbólico da escolha se dá quando se está no âmbito de importantes decisões a tomar, como no caso da escolha da carreira, onde trabalhar, com quem casar. Ver SCANLON, 1998, p. 251-253. Vejamos, também, como eles funcionariam para fundamentar a rejeição razoável do princípio de intervenção paternalística. Se poderia dizer que essa interferência (a) anularia a possibilidade das pessoas em fazerem escolhas com significativo valor instrumental, (b) interferiria nas escolhas que possuem importante valor representativo, isto é, na forma que as pessoas moldam suas vidas e expressam seus valores, (c) estigmatizaria as pessoas sob interferência como imaturos ou incompetentes. Ver SCANLON, 1998, p. 254-255. 
apelando às razões que temos para querer os resultados que dependem da forma que respondemos quando apresentados à alternativas, fazendo referência a um ilustrativo exemplo. Veja-se o caso de alguém que não leva em consideração todos os avisos das forças tarefas públicas a respeito da remoção de lixo radioativo de uma área residencial e sai para caminhar sem levar em conta o que está ocorrendo. Essa pessoa terá responsabilidade substantiva pelo seu próprio dano. E isso parece ser assim porque ela poderia escolher entre as alternativas colocadas, estando em uma boa posição para avaliar os possíveis resultados (SCANLON, 1998, p. 256-258). Disso resulta uma concepção de punição bastante acertada e exequível, pois é tomada como uma penalidade infligida àquele que agiu de forma errada, podendo se dar por multa ou perda de liberdade, mas não é tomada como uma condenação moral absoluta, que puniria a ação livre do sujeito. Isso é assim porque Scanlon parece estar defendendo uma concepção de censura e responsabilidade que está mais próxima do âmbito legal do que do âmbito moral no sentido específico do termo (SCANLON, 1998, p. 263-267) ${ }^{16}$.

Uma forma bastante evidente para esclarecer a respeito da conexão entre responsabilidade e escolha é observar o que caracteriza uma avalição moral. Em uma compreensão tradicional, a avaliação moral estaria associada à tese do mérito que, em resumo, afirma que o sujeito deve ser elogiado ou censurado pela sua ação uma vez que possui o livrearbítrio para escolher. Diferentemente, Scanlon defende uma concepção de responsabilidade que está conectada a um escopo específico da avalição moral. Aqui, o sujeito pode ser criticado, o que significa ser

${ }_{16}$ Geralmente o conceito de censura (blame) está associado às ideias de avaliação (negativa do caráter) e punição. Para Scanlon, ela envolve mais que avaliação e não envolve punição, revelando um aspecto intersubjetivo e, tal como uma atitude reativa, está ligada às expectativas interpessoais. Não é uma avaliação de caráter somente, mas uma identificação de uma ação errada, isto é, uma avaliação negativa de uma ação. Tal como responsabilidade, censura é uma questão de prática social, isto é, que se dá entre indivíduos que estabelecem suas obrigações recíprocas. Ver SCANLON, 2010, p. 122-214. Joel Feinberg defende uma posição semelhante ao afirmar que uma concepção tradicional de responsabilidade moral seria incapaz, em princípio, de aplicação precisa e consistente, como no caso da responsabilidade legal. Estabelece um interessante contraste entre os juízos de responsabilidade legal e de responsabilidade moral, ressaltando o aspecto internalista do âmbito moral em razão da ausência de influências de considerações práticas, imunidade à vagueza e caráter absoluto e regular. O ponto central defendido é que uma concepção de responsabilidade moral que excluísse toda arbitrariedade (causas externas) não seria uma concepção exequível. Vejamos um exemplo: uma pessoa atira em outra e a mata. A lei a julga responsável pelo crime e a enforca. Outro homem, exatamente com os mesmos motivos, atira em seu inimigo, mas erra. A lei não pode julgá-lo responsável por um homicídio porque ele não causou a morte de ninguém, apenas pode responsabilizá-lo por tentativa de homicídio, o que implicaria em uma pena diferenciada. Mas, do ponto de vista moral, ele apenas teve sorte, uma vez que sua intenção foi a mesma e seu ato foi igual ao daquele que foi enforcado. Ver FEINBERG, 1962, p. 340-348. 
responsabilizado, se agir de forma errada, o que implicaria em agir de forma não permitida pelos princípios que ninguém poderia razoavelmente rejeitar. Disso resulta uma concepção mais restrita de culpa e censura, pois serão tomadas apenas como atitudes de reprovação (auto ou hetero) sobre as violações dos direitos comuns, considerando as pessoas como racionais e que agem sob o controle da razão. Essa tese pode ser compatível com a tese causal, mas não será compatível com a concepção de livre-arbítrio como assegurada pela tese do mérito. Nas palavras de Scanlon:

As razões para meu revisionismo (se minha concepção for de fato revisionista) não tem nada a ver com estipulações sobre o livre-arbítrio. Para mim, nenhuma escala de liberdade ou autodeterminação poderia fazer a Tese do Mérito moralmente aceitável. Eu estou defendendo, entretanto, que a crítica (avaliação) moral, como eu a entendo, é compatível com a Tese Causal. ${ }^{17}$

A conclusão a que Scanlon chega é que mesmo que o determinismo fosse verdadeiro, ainda assim seria aplicável a censura às ações que um sujeito tivesse praticado estando sob as condições da ação voluntária ${ }^{18}$. Importante frisar que, para ele, a liberdade não precisa existir para a possibilidade da responsabilidade. Basta que o agente possa governar a si mesmo e isso significa em ser sensível à força de razões e às distinções e relações entre elas. Também, se sua resposta a essas razões em geral determina suas atitudes e ações subsequentes (SCANLON, 1998, p. 281) ${ }^{19}$. A noção de responsabilidade postulada por Scanlon é a da responsabilidade substantiva, de forma que um agente teria

17 SCANLON, 1998, p. 275: "The reasons for my revisionism (if my view is indeed revisionist) have nothing to do with concerns about free will. To my mind, no degree of freedom or selfdetermination could make the Desert Thesis morally acceptable. I am claiming, however, that moral criticism as I understand it is compatible with the Causal Thesis".

18 Scanlon aponta para três precondições essenciais para se realizar a avaliação moral, o que implicará que uma ação seja censurável e que o agente seja responsável por ela: (i) a ação deve ser atribuída ao agente; (ii) o agente deve ter conhecimentos dos fatos; (iii) o agente deve possuir certas capacidades mentais de pensamento, juízo e inferência. Ver SCANLON, 1998, p. 277-280. A noção de censura defendida por Scanlon envolve mais que avalição do caráter do agente e não envolve a ideia de punição, mas implica em uma identificação de uma ação errada e estabelece obrigações recíprocas entre os agentes. Ver SCANLON, 2010, p. 122-214.

19 Fischer e Ravizza defendem uma posição semelhante, a saber, a de que a responsabilidade moral pelas ações estaria associada com o controle de direcionamento (guidance control) dos eventos ligados a essa ação, não necessitando lidar com o conceito de liberdade. $\mathrm{O}$ argumento seria o seguinte: Dado que os agentes possuem controle sobre a sequência efetiva dos eventos que levam a uma ação, eles são responsáveis por essa ação, não sendo necessário o controle regulador (regulative control), isto é, a habilidade de agir de outra maneira. Ver FISCHER; RAVIZZA, 1991, p. 266-270. 
uma obrigação para cumprir. Então, para a imposição da obrigação, seriam necessárias duas coisas centrais, a saber (i) a ação deve poder ser atribuída ao agente, ou, dito de outro modo, a ação deve ser voluntária e (ii) deve se usar um princípio para validar a obrigação da ação que não possa ser razoavelmente rejeitado (SCANLON, 1998, p. 385-386).

Com isso em mãos, retornemos ao caso de Ariel. Sua ação poderia ser considerada como não determinada em razão de se fundamentar em uma escolha que concluiu uma deliberação e, assim, ele poderia ser responsabilizado moralmente pelos atos cometidos? A resposta parece ser positiva. Vejamos de que maneira. Vendo o caso sob a ótica de uma responsabilidade substancial, Ariel possuía obrigações morais para cumprir, uma vez que fazia parte de uma comunidade moral. Até aqui, sem problemas, pois ele fazia parte de uma família e de uma sociedade, mantendo relações com irmãos, mãe, tio, filhas, ex-mulher, colegas de trabalho etc. Isso quer dizer que ele já obedecia a uma série de obrigações, tais como a de proteger suas filhas e sua mãe, por exemplo. Seria razoável, em apenas uma dada circunstância, não se sentir obrigado a cumprir as regras que já foram aceitas? Importante ressaltar que ele parece ter escolhido entre as alternativas colocadas e parecia estar em uma boa posição para avaliar os possíveis resultados de seus atos, uma vez que assumia seus deveres privados e públicos, desempenhando seu papel de cidadão e membro de uma família. Dessa maneira, a censura e a punição devem ter a forma de uma penalidade em razão dele ter agido de forma errada, não sendo uma condenação do ponto de vista do olho de Deus. E por que ele teria agido de forma errada? Porque teria agido de uma forma não permitida pelos princípios que ninguém poderia razoavelmente rejeitar, como os princípios da dignidade humana e autonomia. A responsabilidade de Ariel se daria em um âmbito das obrigações morais comuns que são afirmadas pelos membros de uma comunidade moral. Talvez, apenas um ponto de vista cético exterior poderia livrá-lo da responsabilidade moral. Mas, qual a legitimidade desse ponto de vista, uma vez que estamos refletindo do interior mesmo de uma comunidade moral?

\section{IV}

Nessa parte final do texto, procuraremos estipular um argumento a respeito de um tipo de responsabilidade moral razoável que pode estar contida na teoria da justiça como equidade de John Rawls, podendo ser compreendida, também, como um modelo compatibilista e coerentista 
de responsabilidade que pode ser uma boa resposta a um argumento determinista de tipo psicológico. A forma de entender a responsabilidade se dará pela capacidade do agente ser razoável ou agir razoavelmente.

Vejamos isso a partir da forma como a justiça como equidade estabelece os preceitos da discussão razoável em sua proposta de uma concepção política freestanding de justiça. Sendo uma pessoa razoável aquela que tem consciência dos limites da razão e do juízo, ela reconhecerá certos preceitos para orientar a deliberação e a discussão no âmbito público. Esses preceitos de razoabilidade são: (i) disposição para alcançar o acordo razoável na discussão política; (ii) estabilidade psicológica para encontrar desacordos substanciais sobre questões básicas (questões constitucionais e de justiça básica); (iii) disposição para creditar aos outros uma certa boa-fé, aceitando a diversidade (RAWLS, 1989, p. $478-479)^{20}$.

O que vai interessar aqui é ver como essa concepção política de justiça que está sendo construída a partir do critério da razoabilidade ou aceitabilidade (e não a partir do critério de verdade) não precisa estar comprometida nem com uma concepção tradicional de responsabilidade moral, que se basearia no livre-arbítrio e nem com uma posição determinista, que invalidaria toda a responsabilização do agente. Mais especificamente, queremos ver se essa concepção de responsabilidade moral razoável pode servir de resposta a uma posição determinista de tipo psicológica, a saber, que invalidaria a responsabilidade em razão da impossibilidade da determinação mental. Nela, a ação moral verdadeiramente responsável deveria pressupor uma escolha verdadeira pelo o que se é, isto é, pelo tipo de pessoa que se é; e como as pessoas não podem escolher verdadeiramente como são, elas não seriam verdadeiramente responsáveis por suas ações. Essa compreensão de responsabilidade moral determinística pode ser encontrada em Galen Strawson, por exemplo, que conecta em última instância a responsabilidade da ação com uma escolha verdadeira sobre o tipo de pessoa que se é, a saber, com autodeterminação. Ele procura provar a

${ }_{20}$ Por ser uma disposição, a ação razoável ou a razoabilidade está sendo tomada como uma virtude necessária ao agente para sua deliberação, pois exigirá do mesmo uma disposição prática de agir a partir do critério de reciprocidade e uma disposição intelectual de reconhecimento da limitação racional para o estabelecimento da justificação última do que é o justo. Veja-se que a exigência que é feita ao agente se dará em um âmbito público antes que puramente moral, uma vez que os deveres assumidos serão dados por um reconhecimento social antes que por um método de descoberta de valores morais objetivos totalmente independentes das crenças dos agentes. Ver RAWLS, 1996, p. 48-58. 
impossibilidade da responsabilidade moral das ações com o seguinte argumento básico ${ }^{21}$ :

i) A ação moral verdadeiramente responsável pressupõe uma escolha verdadeiramente responsável pelo que se é (o tipo de pessoa que se é);

ii) As pessoas não podem escolher verdadeiramente pelo que são (não podem se autodeterminar);

iii) Logo, as pessoas não são verdadeiramente responsáveis por suas ações (STRAWSON, 1994, p. 6-7).

Veja-se que a síntese do argumento é a de que uma vez que o agente não possui capacidade de autodeterminação mental, ele não poderia ser responsabilizado moralmente por suas ações. Isso seria significativo no caso de Ariel, pois implicaria sua isenção de responsabilidade moral. O principal problema que pode ser apontado nesse tipo de argumento é a tentativa de estabelecer uma conexão última entre a responsabilidade da ação do agente com uma capacidade última de autodeterminação mental, conexão essa que parece falaciosa ao primeiro olhar. Vejamos mais detalhadamente as razões da falácia do argumento. Iniciemos com o uso problemático do termo 'verdadeiramente' (truly). De fato, para se falar de responsabilidade moral no sentido de ser premiado ou castigado em seu sentido último, como na imagem de céu/inferno, o agente teria que ser verdadeiramente responsável pelo o que ele é, o que implicaria na capacidade de escolha de sua personalidade, caráter, tendências, emoções etc ${ }^{22}$. Como é fartamente sabido, existem circunstâncias

${ }^{21} \mathrm{O}$ argumento básico, usado por Gale Strawson, é o que segue: (1) Ninguém pode ser causa sui, isto é, ninguém pode ser causa de si mesmo; (2) A fim de ser moralmente responsável (verdadeiramente) por uma ação, o agente teria que ser causa sui; (3) Portanto, ninguém pode ser moralmente responsável (verdadeiramente). Importante frisar que essa posição independe da tese do determinismo ser verdadeira ou falsa, e isso por estar baseada nas condições mentais do agente em poder determinar suas próprias características de personalidade, temperamento etc., preferencialmente do que relacionada a uma ordem de causalidade que explicaria necessariamente todos os eventos. Ver STRAWSON, 1994, p. 5.

22 Mas é claro que isso não implica em dizer que o agente não pode ser responsável por seu caráter, ao menos em um sentido prospectivo, isto é, como uma responsabilidade em tomar um certo traço de caráter desejável, isto é, um certo traço comportamental permanente que é desejável por possibilitar uma vida bem-sucedida. Veja-se um interessante exemplo dado por R. Audi a esse respeito. Jean é desonesta, mas tem a decência em se sentir culpada por isso. Alguns de seus valores se contrapõem à desonestidade e ela deseja ser uma pessoa melhor. Possivelmente a desonestidade de Jean foi formada em sua infância, dada por seu ambiente familiar. Dado essa circunstância externa, Jean não tem uma responsabilidade genética sobre a desonestidade. Isso não implica em dizer que ela não será responsável pelos atos desonestos, uma vez que ela é responsável, ao menos parcialmente, por mudar seu caráter para ser honesta (AUDI, 1997, p. 189-190). Ver a distinção feita por Audi entre responsabilidade genética, retencional e prospectiva (AUDI, 1997, p. 188). Identificamos como correta essa noção aristotélica de responsabilidade sobre o caráter, de forma que o nosso caráter recai sobre nosso controle voluntário, uma vez que o agente é responsável pelo exercício de atividades sobre os objetos específicos que formam as disposições de caráter, 
externas à vontade do agente para a constituição de sua identidade, como se pode ver ao olharmos para a herança genética, ou para a situação cultural-econômica-familiar, ou mesmo para situações traumáticas não voluntárias que podem contribuir para uma mudança significativa na identidade do sujeito. Mas, se abandonarmos a pretensão de falar em uma responsabilidade moral última, como uma responsabilidade moral per se, não se vê claramente um ganho significativo no uso do termo 'verdadeiramente', uma vez que estaríamos em um âmbito mais fraco de exigência.

Em segundo lugar, há, também, um uso problemático de um outro termo no argumento, a saber, o 'pelo que se é', isto é, o tipo de pessoa que se é. Novamente, se abandonarmos a ideia de uma responsabilidade última e estabelecermos as exigências em um nível político e jurídico, não seria necessário pensar que o agente só seria responsável por seus atos no momento em que ele pudesse escolher o tipo de pessoa que é. Essa premissa parece defender que, quando se age por uma razão, o que se faz é em função do que se é (mentalmente falando). Mas isso é falso, ao menos parcialmente, uma vez que se poderia agir por uma razão quando se age em função do que se pode ser.

Com isso, se pode identificar uma falácia da dicotomia no argumento, pois ele parece pressupor uma visão dicotômica de mundo, em que teríamos, de um lado, a vontade livre do sujeito em escolher suas características mentais e, de outro, os fatos externos que causalmente constituem o sujeito. A pergunta relevante aqui é a de se seríamos obrigados ou não a aceitar esse tipo de visão? Essa obrigatoriedade seria lógica, factual ou metafísica? Antes, poderíamos pedir uma prova, então, da existência dessas duas esferas antagônicas, a dos fatos e da vontade. Até termos uma prova suficiente da dicotomia, podemos continuar com uma visão de mundo em que fatos e normas coexistem.

Partindo desse pressuposto, o da superação da dicotomia fato/ valor, vejamos o ganho que podemos ter ao adotarmos um modelo coerentista como o de Rawls, por exemplo, para se pensar a respeito da responsabilidade moral. Pensamos ser possível substituir o 'verdadeiramente' pelo 'razoavelmente' e o 'pelo que se é' por 'o que se pode ser' e, assim, teríamos:

i) A ação justa razoavelmente responsável pressupõe uma escolha razoavelmente responsável pelo o que se pode ser;

ii) As pessoas podem escolher razoavelmente como podem ser;

significando que nós somos responsáveis por nos tornarmos o tipo de pessoas que somos. Ver ARISTÓTELES, 1999, p. 38-39 (EN III, 5, 1114 a 4-31). Sobre o tema da responsabilidade sobre o caráter, ver o interessante artigo de Susan Meyer em MEYER, 2006, p. 153-156. 
iii) Logo, as pessoas podem ser razoavelmente responsáveis por suas ações.

Antes de tentarmos explicar o argumento, é importante ressaltar o papel crucial que a categoria de razoabilidade exerce na concepção de justiça como equidade. A teoria normativa rawlsiana exige do sujeito uma disposição de propor e cumprir os termos equitativos de cooperação, bem como uma disposição para reconhecer os limites da razão em justificar arquimedianamente os juízos políticos proferidos pelos indivíduos, isto é, ela exigirá o reconhecimento dos limites da razão, o que é uma outra maneira de dizer que ela exigirá que o sujeito seja razoável. Mas o que isso representa? Que o sujeito deve se dispor a partir da ideia de sociedade como um sistema equitativo de cooperação para o estabelecimento dos princípios de justiça porque já faz uso da ideia de reciprocidade e se dispor a reconhecer o fato do pluralismo razoável e o fato da opressão, que é igual a reconhecer a existência de várias convicções morais sobre o bem em sociedades complexas contemporâneas como uma característica permanente e, também, que a única forma de alcançar uma unidade moral absoluta seria pelo uso da força do Estado para obrigar todos os sujeitos a aceitar uma mesma concepção de bem. Esse parece ser um posicionamento de aceitação da falibilidade humana em alcançar a justificação absoluta das crenças práticas e, por isso, não exigiria do sujeito político o conhecimento do critério último de justificação, isto é, sua verdade ${ }^{23}$.

Com isso em mãos, vejamos agora como podemos entender esse argumento de uma responsabilidade moral razoável. O termo 'razoavelmente' significaria aqui que se seguiu os preceitos da discussão razoável em um âmbito de pluralismo moral, o que implicaria tomar o razoável pelo o que tem aceitabilidade social. Assim, ser responsável por uma ação não seria ser responsável nem pelo que se é e nem por todas as suas consequências. Antes, é uma responsabilidade que estaria centrada na deliberação do agente que pesa razões e escolhe a melhor alternativa. Por isso, o agente pode ser responsabilizado pelo tipo de pessoa que ele pode ser, pois tem capacidade de agir a partir de um senso de justiça e uma concepção de bem, de maneira a poder agir de forma justa e a deliberar sobre os melhores meios para a realização dos fins e,

${ }^{23}$ A exigência de razoabilidade (reasonableness) é explicada nesses termos por Rawls: "O primeiro aspecto básico do razoável é, portanto, a disposição de propor termos equitativos de cooperação e cumpri-los, desde que os outros também o façam. O segundo aspecto básico, como agora revejo, é a disposição de reconhecer os limites do juízo e aceitar suas consequências para o uso da razão pública na condução do exercício legítimo do poder político em um regime constitucional" (RAWLS, 1996, p. 54). Sobre a razoabilidade de uma concepção de justiça, ver RAWLS, 1999, p. 277-285. 
assim, sua ação pode ser responsabilizada. No caso de Ariel, significaria dizer que ele foi responsável pelos atos cometidos em razão de ter tido a capacidade de deliberar e escolher a melhor alternativa, uma vez que ele seria racional e razoável num grau suficiente para ser um cidadão, e isso implicaria em considerar sua responsabilidade como prospectiva, mas não genética. Não se trataria de uma responsabilidade última, é claro, mas de uma concepção exequível de responsabilidade moral, que estaria circunscrita a um âmbito de pluralismo moral razoável. Não seria essa uma alternativa mais eficiente de exigência moral em razão de sua exequibilidade?

\section{Referências}

ARISTÓTELES. Ethica Nicomachea. Ed. I. Bywater. Oxford: Oxford University Press, 1894 (Reimp. 1962). 1999.

. Nicomachean Ethics. Transl. Terence Irwin. 2. ed. Indianapolis: Hackett,

AUDI, Robert. Moral Knowledge and Ethical Character. New York: Oxford University Press, 1997.

DENNETT, Daniel. Freedom Evolves. New York: Viking Penguin, 2003.

DWORKIN, Ronald. Justice for Hedgehogs. Cambridge, Mass.: Harvard University Press, 2011.

EHRENFREUND, Max. "Cleveland Kidnapping victims Amanda Berry, Gina DeJesus, Michelle Knight post video". The Washington Post, July 9, 2013.

FEINBERG, Joel. "Problematic Responsibility in Law and Morals". The Philosophical Review, v. 71, n. 3, 1962, p. 340-351.

FISCHER, John Martin; RAVIZZA, Mark. "Responsibility and Inevitability". Ethics, v. 101, n. 2, 1991, p. 258-278.

FRANKFURT, Harry. "Freedom of the Will and the Concept of a Person". The Journal of Philosophy, v. 68, n. 1, 1971, p. 5-20.

KANT, Immanuel. Groundwork of the Metaphysics of Morals. Trasl. Mary Gregor. New York: Cambridge University Press, 2010.

KORSGAARD, Christine. The Sources of Normativity. New York: Cambridge University Press, 1996.

MEYER, Susan. "Aristotle on the Voluntary". In: KRAUT, Richard (Ed.). The Blackwell Guide to Nicomachean Ethics. Oxford: Blackwell, 2006, p. 137-157.

NAGEL, Thomas. "Moral Luck". In: Mortal Questions. New York: Cambridge University Press, 1979, ch. 3. Rep. in: STATMAN, Daniel. Moral Luck. New York: State University of New York Press, 1993, p. 57-71.

. The View from Nowhere. Oxford: Oxford University Press, 1986.

NOWELL-SMITH, P. "Freewill and Moral Responsibility". Mind, New Series, v. 57, n. 225,1948, p. $45-61$. 
PETERS, Mark. "Ariel Castro, man who held 3 women captive, found dead". The Wall Street Journal, Sept. 4, 2013.

RAWLS, John. (1971). A Theory of Justice. Revised Edition. Cambridge, Mass.: Harvard University Press, 1999.

. "The Domain of the Political and Overlapping Consensus". New York University Law Review, v. 64, 1989, p. 233-255. Rep. in: RAWLS, J. Collected Papers. Cambridge, Mass.: Harvard University Press, 1999, p. 473-496. . Political Liberalism. New York: Columbia University Press, 1996.

SCANLON, Thomas. What We Owe to Each Other. Cambridge, Mass.: Harvard University Press, 1998.

. Moral Dimensions: permissibility, meaning, blame. Cambridge, Mass.: Harvard University Press, 2010.

SKINNER, B. F. The Behavior of Organisms: an experimental analysis. New York: Appleton Century-Crofts, 1938.

STRAWSON, Galen. "The Impossibility of Moral Responsibility". Philosophical Studies, v. 75, n. $1 / 2,1994$, p. 5-24.

STRAWSON, Peter. "Freedom and Resentment". Proceedings of the British Academy, v. XLVIII, 1962. Rep. in: STRAWSON, P. Freedom and Resentment and Other Essays. London: Routledge, 2008, p. 1-28.

WALKER, Tim. "Ariel Castro sentenced to life plus 1,000 years in prison for abduction of Amanda Berry, Gina DeJesus and Michelle Knight". The Independent, 01 Aug. 2013.

WILLIAMS, Bernard. "Moral Luck". In: Moral Luck: philosophical papers 1973-1980. Cambridge: Cambridge University Press, 1981, p. 20-39.

$\overline{\text { Press, }} 1985$. . Ethics and the Limits of Philosophy. Cambridge, Mass.: Harvard University

\section{Endereço postal:}

Universidade do Vale do Rio dos Sinos

PPG em Filosofia - Escola de Humanidades

Av. Unisinos, 950 - Centro 1, Bloco A, sala 350 - Cristo Rei

93022-000 São Leopoldo/RS, Brasil

E-mail: deniscoitinhosilveira@gmail.com

Data de recebimento: 01/09/2013

Data de aceite: 12/03/2014 